\title{
3D Transient Thermal Modelling and Experimental Validation of the Temperature Distribution During Laser Heating of Ti6Al4V Alloy
}

\author{
Jihong (Nancy) Yang ${ }^{1, a}$, Shoujin Sun ${ }^{1, b}$, Milan Brandt ${ }^{2, c}$ and Wenyi Yan ${ }^{3, d}$ \\ ${ }^{1}$ CAST Cooperation Research Centre, Swinburne University of Technology, Industrial Research \\ Institute (IRIS). PO Box 218 (H66), Hawthorn VIC 3122, Australia \\ ${ }^{2}$ School of Aerospace, Mechanical and Manufacturing Engineering, RMIT University \\ PO Box 71 Bundoora Victoria 3083, Australia \\ ${ }^{3}$ Department of Mechanical and Aerospace Engineering, Monash University, Clayton VIC 3800, \\ Australia \\ a jyang@swin.edu.au
}

Keywords: Finite element modelling, temperature distribution, laser heating, Ti6Al4V alloy

\begin{abstract}
A three 3D transient finite element model has been developed to predict the temperature distribution in Ti6Al4V alloy plate workpiece. It is found that the temperature profile is strongly dependent on the parameters of the laser beam and material properties. Also the thermal model results were compared with results produced by experimental work and these show close agreement.
\end{abstract}

\section{Introduction}

Titanium alloys are difficult to machine due to their high strengths, low thermal conductivity and high chemical reactivity. This means that conventional machining of titanium alloys is a low productivity process with high materials running costs - tool and coolant [1].

Laser assisted machining (LAM) has been considered as an alternative to conventional machining of hard and/or difficult-to-process materials, such as metallic alloys and silicon nitride ceramics [2-5]. The main advantage that laser assisted machining has over conventional machining is the higher material removal rate, increased productivity, and longer tool life.

Modeling of LAM is of great importance, since a better process understanding will allow optimization and control of the machining process of titanium alloys [6]. We have been developed 3D finite element model to predict the heat affected zone (HAZ) caused by laser heating of Ti6Al4V alloy process [7]. This work focus on to develop the 3D transient finite element model for the moving laser beam to predict the 3D temperature distribution on a Ti6Al4V alloy plate workpiece. The thermal model results were compared with results produced by experimental work and these show close agreement.

\section{Thermal Modelling}

The origin of an $x-y-z$ coordinate system was chosen at the centre of the laser beam on the work piece surface. The depth of the work piece was aligned in $\mathrm{z}$ direction and increases with increasing $z$. The workpiece moves in the $-y$ direction with a constant velocity $U$ as shown in Figure 1 . The laser beam and the coordinate system are fixed and the work piece moves at velocity U. In this work, the estimation of heat treatment is based on the following assumptions:

1) The laser beam is regarded as a base mode Gaussian beam incident normally at the top surface of the workpiece.

2) The Gaussian distribution of absorbed laser heat flux $q(x, y)$ is given by [8]:

$$
q(x, y)=\frac{2 P}{\pi b^{2}} \exp \left(-\frac{2\left(x^{2}+y^{2}\right)}{b^{2}}\right)
$$


3) The thermo-physical properties are dependent on temperature [9].

4) The workpiece material is homogeneous.

5) The ambient temperature is $22^{\circ} \mathrm{C}$.

6) Air convection coefficient is $50\left[\mathrm{~W} / \mathrm{m}^{2} \mathrm{~K}\right]$.

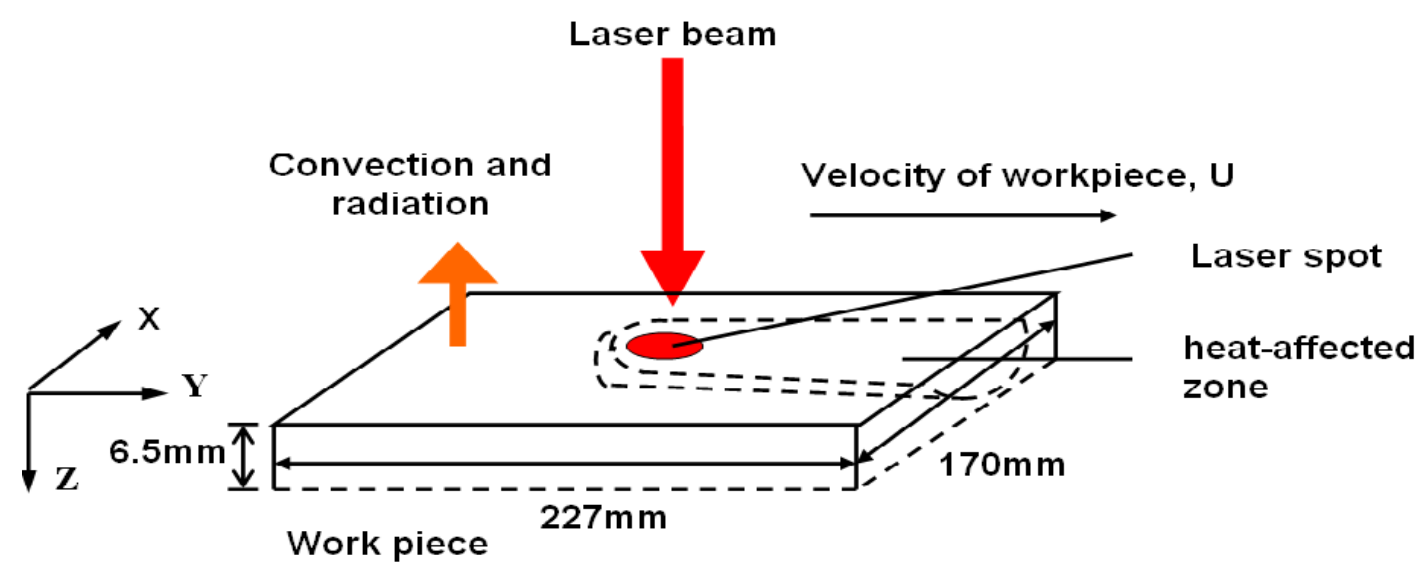

Fig. 1 A schematic illustrating of laser heating trial.

The $3 \mathrm{D}$ transient time-dependent heat conduction in the material underneath the irradiated surface is described by Equation (2) [10]:

$$
\rho c_{p}\left(\frac{\partial T}{\partial t}+U \frac{\partial T}{\partial y}\right)=\frac{\partial}{\partial x}\left(k \frac{\partial T}{\partial x}\right)+\frac{\partial}{\partial y}\left[k \frac{\partial T}{\partial y}\right]+\frac{\partial}{\partial z}\left[k \frac{\partial T}{\partial z}\right]
$$

The initial condition at time $\mathrm{t}=0$ is given by

$\mathrm{T}(\mathrm{x}, \mathrm{y}, \mathrm{z}, 0)=\mathrm{T}_{0}$

The natural boundary condition takes into account the imposed heat flux, radiation and convection at the laser irradiated surface and can be defined by

$-k \frac{\partial T}{\partial z}=q(x, y)-h\left(T-T_{0}\right)-\sigma \varepsilon\left(T^{4}-T_{0}^{4}\right)$

A thermal numerical simulation was performed to predict the temperature distribution on a Ti6A14V alloy (Grade 5) plate workpiece. The finite element model was created in ANSYSs (version 11.0 SP1). The moving laser beam is symmetric so that the semi-circular Gaussian distribution of heat flux was defined. A plane of symmetry was assumed and only half of the workpiece was modeled. The dimension of the modelled workpiece was of width $10 \mathrm{~mm}$, length $20 \mathrm{~mm}$ and thickness $6.5 \mathrm{~mm}$. The initial temperature was $22{ }^{\circ} \mathrm{C}$. The bottom face was maintained at $22^{\circ} \mathrm{C}$.

\section{Results and Experimental Validation}

The results of the ANSYS program can be displayed in many ways. The 3D temperature distribution is shown for the case of $500 \mathrm{~W}$ laser power, $17.35 \mathrm{~mm} / \mathrm{sec}$ laser scan speed and $4.4 \mathrm{~mm}$ spot diameter for the different times in Fig 2 ((a), (b) and (c)). 

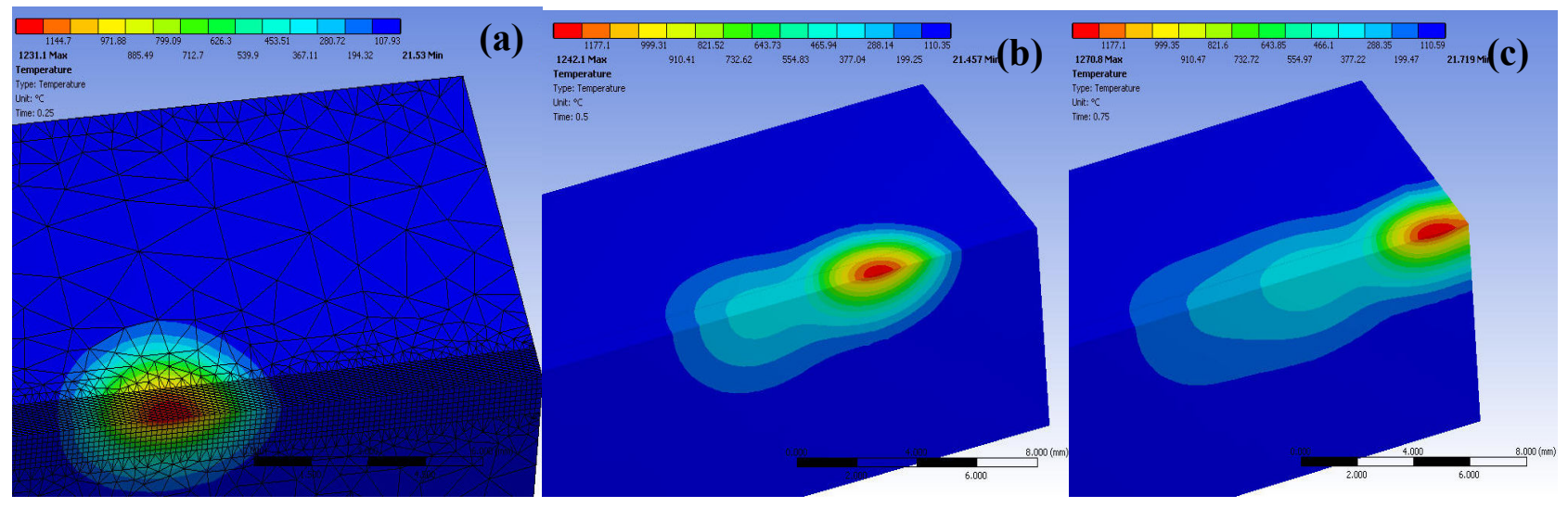

Fig. 2 The 3D temperature distribution of Ti6Al4V alloy workpiece (500W laser power, $17.35 \mathrm{~mm} / \mathrm{s} \mathrm{scan}$ speed, $4.4 \mathrm{~mm}$ spot diameter); (a) at $0.25 \mathrm{~s}$; (b) at $0.5 \mathrm{~s}$; (c) at $0.75 \mathrm{~s}$.

The workpiece material was a Ti6Al4V alloy plate of width $170 \mathrm{~mm}$, length $227 \mathrm{~mm}$ and thickness $6.5 \mathrm{~mm}$. The Rofin-Sinar $2.5 \mathrm{~kW} \mathrm{Nd}$ : YAG laser system was utilized to generate a laser beam. The titanium alloy (Ti6Al4V) tests were carried out at four laser scanning speed (33.33, $66.66,100,133.30,166.70 \mathrm{~mm} / \mathrm{s})$ and eight laser power levels $((500,750,1000,1250,1500,1750$, 2000 and $2378 \mathrm{~W}$ ). In this case the beam diameter is equal to $6.2 \mathrm{~mm}$, the thermal conductivity $k$ is $7 \times 10^{-3} \mathrm{~W} / \mathrm{mmk}$ and thermal diffusivity $a$ is $2.9 \mathrm{~mm}^{2} / \mathrm{s}$.

To verify that the model can accurately determine the temperature distribution on the laser heating of a Ti6Al4V alloy plate workpiece process, the model was verified with experimental data. This has been done by comparing the modeling results to real data produced from experiments, where a plate workpiece undergoes translational heating from a moving Nd: YAG laser beam. The robustness of the model can be evaluated with experimental results produced from the heating test on Ti6Al4V alloy plate workpiece.

Fig. 3 compares the experimental results with the FE simulation results for various laser powers (500 to $2378 \mathrm{~W}$ ) and laser scan speeds (13.33 to $166.7 \mathrm{~mm} / \mathrm{s}$ ). The figure shows that the most model results are slightly higher than the experimental results. We can see there is good correlation between the simulated and measured results.

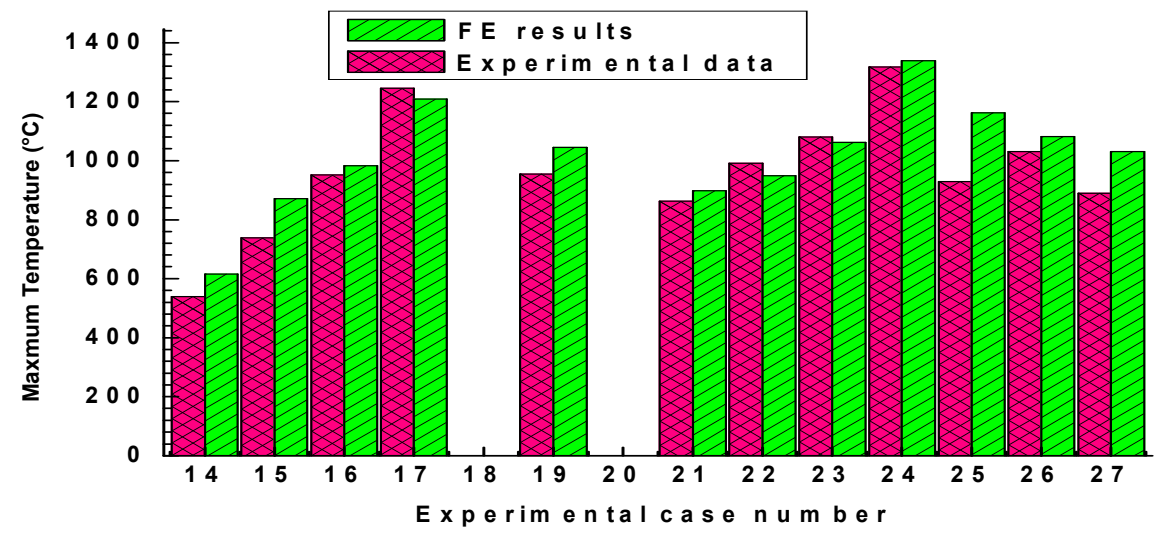

Fig. 3 Comparison of model results to experimental measurements for the different cases. 


\section{Conclusions}

[1] The 3D transient FE thermal model has been successfully developed to analyze the temperature distribution in the Ti6Al4V alloy plate workpiece.

[2] Experimental validation of thermal model was performed using moving laser beam on Ti6Al4V plate workpiece. There is good correlation between FEM and experiment results.

[3] The thermal model can be used to predict the temperature distribution on Ti6Al4V alloy plate workpiece and this provides important information to optimize and improve the LAM technique.

\section{Acknowledgements}

The authors would like to thankfully acknowledge the financial support from the CAST Cooperation Research Centre, Swinburne University of Technology (IRIS).

\section{References}

[1] M. Rahman, Z. G. Wang, Y. S. Wong, Jsme Int. J. Series C- Mech.Syst. Mach. Elem. Manuf Vol. 49(2006), p. 11.

[2] G. Chryssolouris, N. Anifantis, S. Karagiannis, ASME, J. Manuf . Sci. Eng Vol. 119 (1997), p. 766.

[3] J. C. Rozzi, F. E. Pfefferkorn, Y. C. Shin, F.P. Incropera, J. Manuf. Sci. Eng-Trans. Asme Vol. 122(4) (2000), p. 666.

[4] G. Germain, F. Morel, J. L. Lebrun, A. Morel, Laser. Eng Vol. 17(2007), P. 329.

[5] S. J. Sun, J. G. Harris, M. Brandt, Adv. Eng. Mater Vol. 10(6) (2008), P. 565.

[6] B. Shi, H. Attia, R. Vargas, S. Tavakoli, Mach. Sci. Technol Vol. 12(4) (2008), P. 498.

[7] N. Yang, M. Brandt, S. J. Sun, Mater. Sci. Forum Vol. 618-619 (2009), P. 143.

[8] N. B. Dahotre, S. P. Harimkar, in : Laser Fabrication and Machining of Materials, Spring Science+ Business Media, New York (2007).

[9] K. C. Mills, in : Recommended Values of Thermophysical Properties for Selected Commercial Alloys, first ed. Woodhead Publishing Limited, Cambridge ( 2002).

[10] F.P. Incropera, D.P.Dewitt, T. L Bergman, A. S. Lavine, in: Fundamentals of Heat and Mass Transfer, sixth ed. John Wiley \& Sons, New York (2007). 